\title{
Preparation of Low Cost Affinity Chromatographic Matrix and Its Application in Purification of a Lectin Isolated from Mulberry Seeds
}

\author{
Mosammat Jesmin Sultana ${ }^{1, \uparrow, *}$, Mohammad Taufiq Alam², Fazle Rabbi Shakil Ahmed ${ }^{3}$ \\ ${ }^{1}$ Department of Materials Science and Engineering, University of Rajshahi, Rajshahi, Bangladesh \\ ${ }^{2}$ Department of Applied Chemistry and Chemical Engineering, University of Rajshahi, Rajshahi, Bangladesh \\ ${ }^{3}$ Department of Pharmacy, Khwaja Yunus Ali University, Sirajgonj, Bangladesh
}

Email address:

jssumi8@gmail.com (M. J. Sultana),jesmin_mse@ru.ac.bd (M. J. Sultana)

${ }^{*}$ Corresponding author

$\uparrow$ Mosammat Jesmin Sultana is first authors.

\section{To cite this article:}

Mosammat Jesmin Sultana, Mohammad Taufiq Alam, Fazle Rabbi Shakil Ahmed. Preparation of Low Cost Affinity Chromatographic Matrix and Its Application in Purification of a Lectin Isolated from Mulberry Seeds. International Journal of Biomedical Materials Research. Vol. 6, No. 2, 2018, pp. 50-56. doi: 10.11648/j.ijbmr.20180602.14

Received: June 22, 2018; Accepted: July 17, 2018; Published: August 30, 2018

\begin{abstract}
Objective: Uniform sized agarose gel beads were prepared from agarose by emulsification technique. The prepared matrix has been attached with commercially available concanavalin A (conA) and finally it has applied to purify mulberry seed lectin. The present work shows a simple and inexpensive method for the preparation of an affinity matrix for purification of conA specific mulberry seed lectin. Method: Firstly, conA was immobilized on agarose gel beads and coupled to hexadiamine by using amino reactive bifunctional crosslinker (2,4,6-trichloro-1,3,5-trizine). Then it used as affinity matrix for the purification of mulberry seed lectin (designated as MSL). In purification protocol initially conA has been immobilized with agarose. Then MSL have been purified from the seeds of Morus alba L. Result: The agarose beads showed the best uniformity when $2-2.5 \%$ concentration of Tween 80 was used. The newly prepared affinity matrix agarose gel was able to purify MSL with the molecular weight of $22 \mathrm{kDa}$ in a single step. The purified lectin strongly agglutinated with mice, chicken, bovine and human blood types $\mathrm{A}, \mathrm{B}$ and $\mathrm{O}$ erythrocytes respectively. There was no activity found on goat erythrocytes. Conclusion: The present work shows a simple and inexpensive method for the preparation of an affinity chromatographic matrix. The prepared matrix was applied to purify mulberry seed lectin.
\end{abstract}

Keywords: Immobilization, Affinity Matrix, Affinity Chromatography, Epichlorohydrin, Lectin, Hemagglutination

\section{Introduction}

In recent years, the membrane affinity chromatography of biomolecules had a fast development, because their chemical potential essential consistent and capable extend methods of separation and purification [1-5]. Several resources, such as nylon, polysulfone, chitosan, cellulose and cellulose derivatives [6-11] were used to prepare affinity chromatographic matrixes. The synthetic polymeric materials were used for membrane preparation. But some of them are less suitable for ligand immobilization, because their lower compatibility increases the probability for denaturation of the biomolecules. Agarose is highly compatible with biomolecules. In this research affinity chromatography matrix were prepared from agarose by chemical crosslinking. In an enhanced description modification and activation were also carried out after crosslinking. In preparation the effect of crosslinker and activator were investigated. For ligand coupling three immobilization steps were used for matrix preparation such as treatment with Epichlorohydrin, modification with 1, 6-Hexanediamine, activation with 2,4,6trichloro-1,3,5-trizine.

Lectins are a class of proteins that bind sugar specifically and agglutinate cells. It is widely distributed in nature, being found in animals, insects, plants and microorganisms [12]. 
mulberry is the only food and nutritional source for Bombyx mori L. It is the host plant of silkworm which produces silk [13]. The mulberry plants which are standard to grow tall with a top height of 5-6 feet from soil stage and a stalk distance across of 4-5 inches or more is called tree mulberry. The species is native to northern China, and is broadly cultivated and naturalized elsewhere [14]. There is now severe concern for the long-standing genetic viability of red mulberry because of wide-ranging hybridization in some areas [15]. The white mulberry is widely cultivated to give food to the silkworms working in the commercial production of silk. The seeds are extensively spread in the droppings of birds that eat the fruit [14].

Mulberry seeds has lot of therapeutic values so it is used as conventional medicinal plant throughout Southeast Asia especially in Bangladesh. It was brought from the Sericulture Research and Training Institute, Rajshahi, Bangladesh.

Literature shows that mulberry lectin(ML) have been purified by gel filtration followed by ion exchange and hydrophobic chromatographic technique [13]. On the other hand, three electrophoretically homogeneous lectins MSL-1, MSL-2 and MSL-3 were purified from the extract of mulberry seeds by using DEAE-cellulose and CM-cellulose column [16]. The molecular masses of MSL-1, MSL-2 and MSL-3 were to be 175,120 and $89 \mathrm{kDa}$, respectively. However, these techniques were multi-steps, time consuming, lengthy and expensive. We extended this technique by reduce time consuming, cost of processes and also develop the efficiency. ConA immobilized agarose gel beads have been first of all used as affinity media for the purification of mulberry seed lectin. This article mention that the application of prepared affinity matrix to purify a lectin.

\section{Materials and Methods}

\subsection{Preparation of Uniform-Sized Agarose Beads}

A uniform sized agarose gel was prepared by emulsification technique, where $4 \%$ agarose was used as water phase and liquid paraffin was used as oil phase. Additionally, $2.5 \mathrm{wt} \%$ Tween 80 was added as surfactants which might help to prevent the coalescence of agarose gel. So agarose was dissolved in distilled water with containing $0.9 \% \mathrm{NaCl}$ and the solution was heated by micro oven to a temperature above the gelation point of the agarose. The solution was designated as water phase. The mixture of liquid paraffin and Tween 80 was heated to a temperature above the gelation point of the agarose approximately $80^{\circ} \mathrm{C}$ and the solution was designated as oil phase. The oil phase was charged into the water phase and agitated quickly by agitator. A uniform sized emulsion was formed in the reactor. The emulsion was added into second hydrophobic liquid cooled paraffin at $-20^{\circ} \mathrm{C}$ to solidify the agarose droplets into beads. Finally the agarose beads were recovered from the second liquid and washed with distilled water. After washing the gel was screened, standardized mesh No. series as 25, 60, 120, and 270 was used to determine the particle size distribution of a granular material. After screening, the obtained uniform size gel was sent for microscopic view.

\subsection{Cross-Linking of Agarose Gel by Epichlorohydrin}

About $50 \mathrm{ml}$ uniform-sized agarose gels were taken in a $250 \mathrm{ml}$ beaker containing $20 \mathrm{ml}$ of $2 \mathrm{M} \mathrm{NaOH}$ and $5 \mathrm{ml}$ of Epichlorohydrin. The mixture was allowed to react for 2 hours at $40^{\circ} \mathrm{C}$ with constant mixing in a home made rotary mixture to keep the concentration uniform [17]. After reaction, the gels were washed with deionized distilled water until it became neutral (conforming by litmus paper).

\subsection{Modification of Agarose Gel with 1,6-Hexanediamine}

For the modification of agarose gel, $300 \mathrm{ml} 0.2 \mathrm{M}$ of 1,6 hexadiamine solution containing 1.5 gm sodium carbonate decahydrate was mixed with the epoxy cross-linked agarose gels. The reaction was carried out at $60^{\circ} \mathrm{C}$ for 2 hours [18]. After reaction the gels were again washed with distilled water until the gel became neutral.

\subsection{Activation of Agarose Gel with 2,4,6-trichloro-1,3,5-trizine}

Amino modified agarose gel was soaked in $50 \mathrm{ml}$ of $3 \mathrm{M}$ $\mathrm{NaOH}$ solution. It was placed in ice bath and $150 \mathrm{ml}$ of a 0.5 M 2,4,6-trichloro-1,3,5-trizine solution was mixed with homemade mixture in refrigerator for 60 mins. After activation, the gels were rinsed successively with $500 \mathrm{ml}$ of 50 vol $\%$ acetone aqueous solution and 2 liter distilled water was used for washing to remove the unreacted 2,4,6trichloro-1,3,5-trizine.

\subsection{Immobilization of ConA to the 2,4,6-trichloro-1,3,5-trizine Activated Gel}

2,4,6-trichloro-1, 3, 5-trizine activated gel(collected from title 2.4.) was placed into an ice bath and mixed with $0.1 \mathrm{M}$ sodium phosphate buffer, $\mathrm{pH} 7.8$ containing $200 \mathrm{mg}$ of commercially conA with continuos mixing for $12 \mathrm{hrs}$. After coupling, the gel was separated and $150 \mathrm{ml}$ of a $0.5 \mathrm{M}$ ethanolamine aqueous solution was mixed for $8 \mathrm{hrs}$ to block the unreacted triazine groups. Finally the gels were rinsed with 1 liter distilled water [19]

\subsection{Purification of Mulberry Seed Lectin Using Prepared Affinity Matrix}

Mulberry seeds were collected from the Sericulture Research and Training Institute, Rajshahi, Bangladesh. It pulverized in a mortar and pestle to produce fine powder materials and then powder materials was delipidated by refluxing with $40^{\circ}-60^{\circ} \mathrm{C}$ petroleum ether. The delipidated seed $(10 \mathrm{gm})$ was homogenized with $50 \mathrm{ml}$ of $50 \mathrm{mM}$ sodium acetate- $\mathrm{HCl}$ buffer at $\mathrm{pH} 4$ and kept it 3-6 hr at $4^{\circ} \mathrm{C}$ with occasional stirring. The homogenized materials were collected and add $90 \%$ saturated solid ammonium sulphate at 
$4^{\circ} \mathrm{C}$ by slowly stirring. After dissolve all the pellet of solid ammonium sulphate, kept it 3-6 hr. Almost all proteins were precipitate by ammonium sulfate precipitation. Then the precipitate was collected by centrifugation at $10,000 \mathrm{rpm}$ for $10 \mathrm{~min}$ and dissolved it in a minimum volume of $20 \mathrm{mM}$ Tris- $\mathrm{HCl}$ buffer at $\mathrm{pH} 8$ and it was used as crude protein extract. The crude protein was mixed with the affinity chromatographic gel which was previously immobilized with conA. Then the gel was equilibrated with $20 \mathrm{mM}$ Tris- $\mathrm{HCl}$ buffer at $\mathrm{pH} 8$ containing $0.5 \mathrm{M} \mathrm{NaCl}, 1 \mathrm{mM} \mathrm{CaCl} 2,1 \mathrm{mM}$ $\mathrm{MnCl}_{2}$ and $1 \mathrm{mM} \mathrm{MgCl} 2$ and packed in column. The unbound proteins were washed out by the same buffer until the absorption at $280 \mathrm{~nm}$ in HPLC detector became linear. Bound protein was eluted by $20 \mathrm{mM}$ Tris- $\mathrm{HCl}$ buffer at $\mathrm{pH} 8$ containing $0.4 \mathrm{M}$ glucose. The purity was verified by using SDS-PAGE in $16 \%$ polyacrylamide gel electrophoreses as described by Laemmli [20].

\subsection{Determination of the Molecular Weight and Protein Content}

The molecular weight of purified lectin was determine by SDS-PAGE using 16\% polyacrylamide gel, where Myosin (200kDa), $\beta$-Galactosidase $(116.25 \mathrm{kDa})$, Phosphorylase b (97.4kDa), Bovine serum albumin $(66.2 \mathrm{kDa})$, Ovalbumin $(45$ $\mathrm{kDa})$ Carbonic andydrase $(31 \mathrm{kDa})$, Triypsin inhibitor $(21.5$ $\mathrm{kDa})$ and Lysozyme $(14.4 \mathrm{kDa})$ were used as marker proteins. The purified lectin was designated as mulberry seed lectin (MSL). The amount of protein content was determined by the Biuret method [21] using lipid-free Bovine serum albumin as the standard.

\subsection{Hemagglutination Assay}

The hemagglutination assay was performed using different types of erythrocytes: human blood groups (A, B, $\mathrm{O}$ and $\mathrm{AB}$ ) collected from four donors and the chicken, goat and bovine blood was collected from a slaughter house and adult swiss albino mice were collected from the International Centre for Diarrhoeal Disease Research, Bangladesh(icddr, b). All the blood samples were collected in saline and centrifuged at $1200 \mathrm{~g}$ for $10 \mathrm{~min}$. The erythrocyte pellets (RBC) were washed three times and resuspended in the same saline to prepare a $2 \%$ suspension [22]. The activity was tested in 96-well microtiter U-bottomed plates in a final volume of $100 \mu \mathrm{l}$ containing $50 \mu \mathrm{l}$ of protein solution $(2.2 \mathrm{mg} / \mathrm{ml}) \mathrm{which}$ was serially diluted with the same amount $(50 \mu l)$ of hemagglutination buffer $(20 \mathrm{mM}$ Tris- $\mathrm{HCl}$ buffer, $\mathrm{pH} 7.8$ containing $150 \mathrm{mM} \mathrm{NaCl}$ and $10 \mathrm{mM} \mathrm{CaCl}_{2}$ ) and $50 \mu \mathrm{l}$ of $2 \%$ suspension of erythrocytes previously washed with 150 $\mathrm{mM} \mathrm{NaCl}$. After a gentle shaking, the plate was kept at room temperature for $30 \mathrm{~min}$. The visual agglutination titer of the maximum dilution giving the positive agglutination recorded.

\section{Result and Discussion}

\subsection{Preparation of Uniform-Sized Agarose Beads}

Uniform-sized agarose beads were prepared by emulsification method. The diameter of beads 150 to $300 \mu \mathrm{m}$ were obtained in this method (Figure 1).

\subsection{Effect of Emulsifier on Uniformity of Agarose Beads}

Tween 80 was used as emulsifier and it played an important role in formation of the uniform-sized agarose beads. When concentration of Tween 80 was bellow $2 \%$, the agarose beads lost its uniformity. When the concentration was higher than $2.5 \%$ the agarose beads also lost its uniformity. Optimum concentration of Tween 80 was found to be $2-2.5 \%$, when the agarose beads showed the best uniformity (Figure1b).

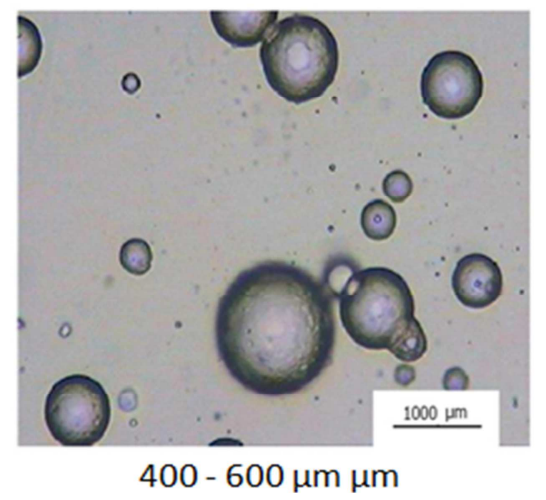

(a)

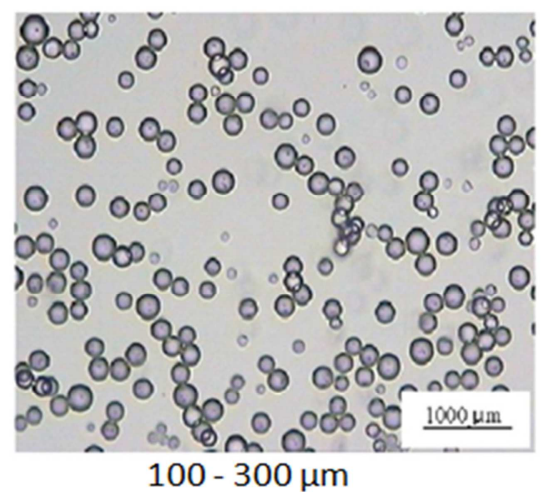

(b)

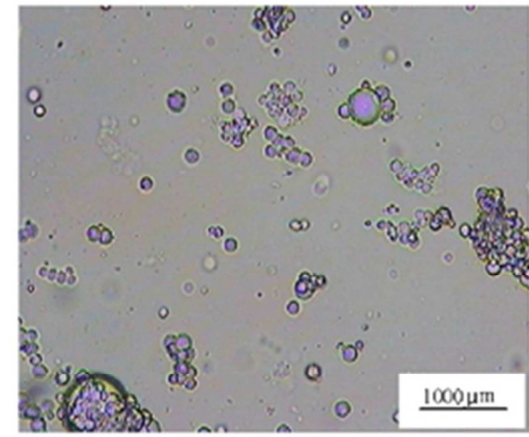

$60-70 \mu \mathrm{m}$

(c)

Figure 1. Optical microscopic photographs of agarose gels prepared by using different amount of Tween-80: (a) 1.5\%, Tween-80 (b) 2.5\% (uniform-sized agarose beads) Tween-80 and (c) $4 \%$ Tween- 80 .

\subsection{Cross Linking of Agarose Gel}

Since the prepared agarose gel beads are mechanically fairly weak, a chemical crosslinking is necessary to ensure that the gel beads will remain stable during subsequent 
modifications and affinity chromatography. Literature shows that commercial agarose is completely soluble in dimethyl sulfoxide at $100^{\circ} \mathrm{C}$ or in $4 \mathrm{M}$ sodium iodide, whereas agarose cross-linked with Epichlorohydrin is essentially unaffected under the similar condition. In our research, the crosslinking was carried out with Epichlorohydrin and the resultant crosslinked agarose beads showed excellent mechanical and chemical stability against HPLC solvent pressure and the chemicals used throughout this study.

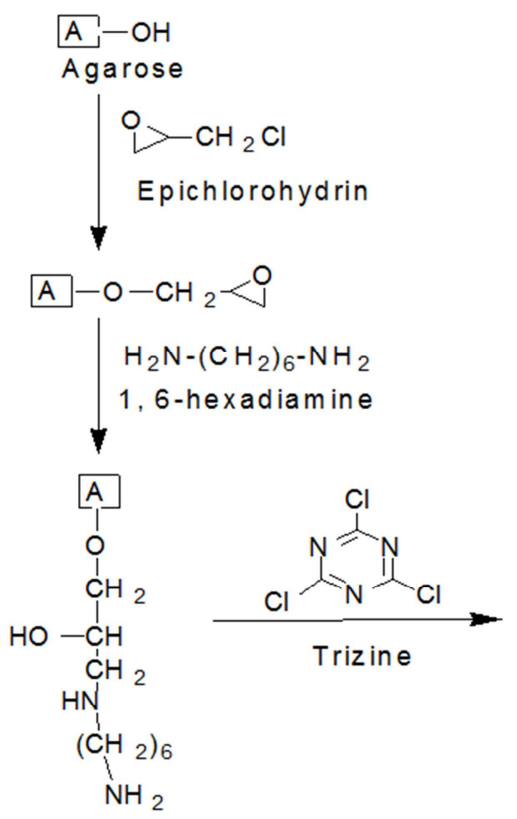

\subsection{Attachment of ConA into the Agarose Matrix for MSL Purification}

At first we have been cross-linked the Epichlorohydrin with agarose gel beads and then 1, 6 hexadiamine have been attached to the cross-linked matrix for modification of the gel Amino modified agarose gel was activated with 2,4,6trichloro-1,3,5-trizine. Finally conA has been immobilized with the Trizine activated gel (Figure 2). The detail schematic representation of the process as follows.

Figure 2. Reaction between conA and the agarose matrix.

\subsection{Purification of Mulberry Seed Lectin by Using Prepared Affinity Matrix and Determination of Molecular Mass}

A lectin was purified from the seed of Morus alba L. (mulberry plant). Mulberry seed lectin (MSL) was purified from the crude extract of mulberry seeds followed $90 \%$ ammonium sulphate precipitation by affinity chromatography on newly prepared affinity matrix (Figure. 3). The eluted fraction of affinity chromatography was showed hemagglutination activity and migrated on SDS-PAGE as a single band with an apparent molecular mass of $22.0 \mathrm{kDa}$ (Figure. 4). So the newly prepared affinity matrix was able to purify MSL in a single step. About $30.1 \mathrm{mg}$ of MSL obtained from $10 \mathrm{~g}$ of mulberry seeds and the purification procedure was summarized in Table 1.

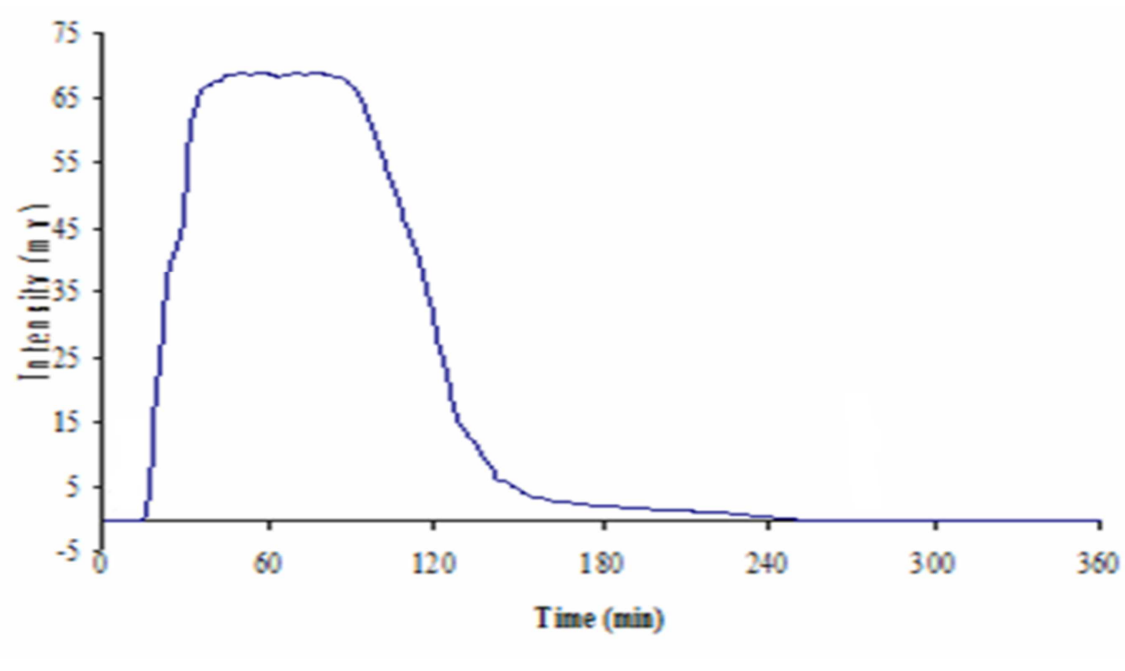




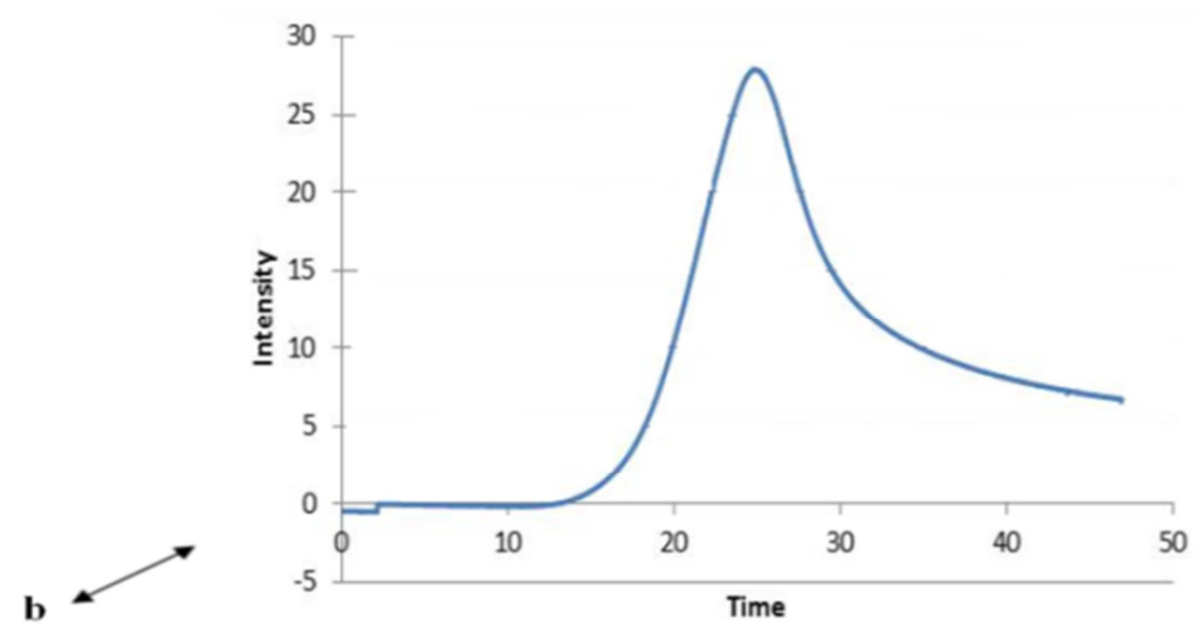

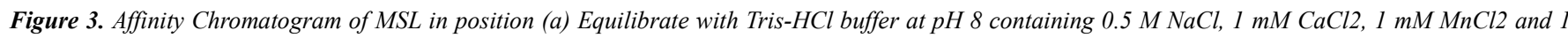
$m M \mathrm{MgCl} 2$; in position (b) Elution of MSL with Tris-HCl buffer at $\mathrm{pH} 8$ containing $0.4 \mathrm{M}$ glucose.

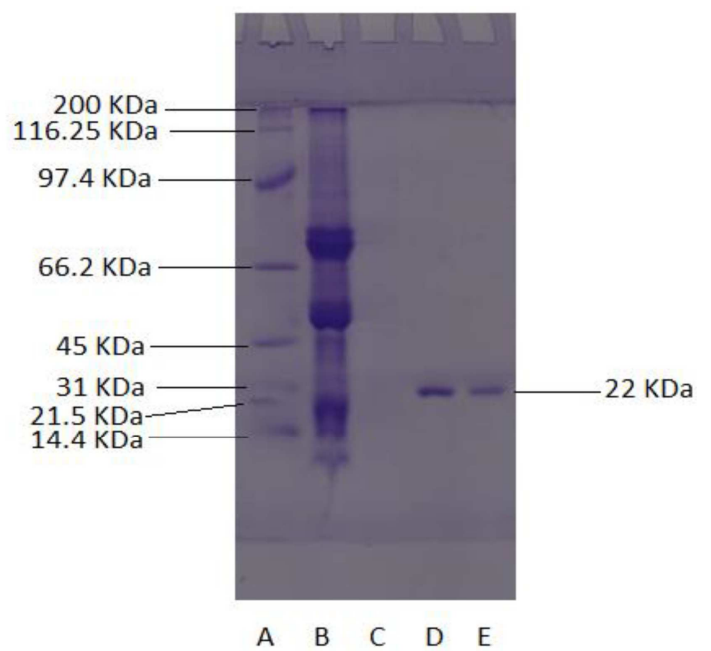

Figure 4. Sodium dodecyl sulfate polyacrylamide gel electrophoresis (SDS-PAGE) was used to identify individual proteins present at various stages of the purification. $A=$ Marker protein, $B=$ Crude extract, $C=$ Unbound protein, $D=$ Affinity purified mulberry seed lectin with high concentration and $E=A$ Affinity purified mulberry seed lectin with low concentration.

\subsection{Determination of the Protein Content}

It was found that $10 \mathrm{gm}$ of mulberry seed contains about $167.4 \mathrm{mg}$ of total protein among them about $30.1 \mathrm{mg}$ is MSL and the remaining $131.2 \mathrm{mg}$ are other proteins. Thus the approximate ratio of MSL and other proteins in mulberry seeds is 1:4. The percentage of yield of purified MSL is $85 \%$ (Table 1).

Table 1. A summary of the purification of MSL.

\begin{tabular}{lllllll}
\hline Purification step & Volume (ml) & Absorbance at $\mathbf{5 4 6} \mathbf{~ n m}$ & $\begin{array}{l}\text { Protein content } \\
(\mathbf{m g} / \mathbf{m l})\end{array}$ & $\begin{array}{l}\text { Total protein } \\
(\mathbf{m g})\end{array}$ & $\begin{array}{l}\text { Lectin activity } \\
\text { (Titer/ml) }\end{array}$ & \% Yield \\
\hline Standard & & 0.41 & 80 & & & \\
Crude extract & 6 & 0.143 & 27.9 & 167.4 & 4096 & $85 \%$ \\
Unbound & 32 & 0.021 & 4.1 & 131.2 & 512 & \\
Bound & 14 & 0.011 & 2.15 & 30.1 & 4096 \\
\hline
\end{tabular}

\subsection{Hemagglutination and Blood Group Specificity Assay}

Hemagglutination assay has been widely used for the measurement of lectin activity. In the hemagglutination test, the micro titration format was employed in U-bottom polystyrene microtiter plates. Hemagglutination assay was performed using mice, chicken, human types $\mathrm{A}, \mathrm{B}$ and $\mathrm{O}$, bovine and goat erythrocytes. The minimum concentration was found to be $0.031 \mu \mathrm{g} / \mathrm{ml}$ in mice, $0.125 \mu \mathrm{g} / \mathrm{ml}$ in chicken, $0.25 \mu \mathrm{g} / \mathrm{ml}$ in human blood types A, B and O erythrocytes and $8 \mu \mathrm{g} / \mathrm{ml}$ in bovine erythrocytes. The result of hemagglutination activity was presented in table 2 . From the result mulberry seed lectin powerfully agglutinated with mice erythrocytes whereas no activity found on goat erythrocytes. 
This behaviour was observed in other lectin also. As for example a lectin from Phaseolus coccineus seed can agglutinate all the human blood groups [23]. Another lectins from Moringa oleifera seed was agglutinated mouse, cow and human erythrocytes [24] and RSB can agglutinate mouse, sheep, and rabbit erythrocytes [25].

Table 2. Hemagglutination activity of MSL with various erythrocytes.

\begin{tabular}{|c|c|c|c|c|c|c|c|c|c|c|c|c|}
\hline \multirow{4}{*}{$\begin{array}{l}\text { MSL } \\
\text { Vs Erythrocytes }\end{array}$} & 1 & 2 & 3 & 4 & 5 & 6 & 7 & 8 & 9 & 10 & 11 & 12 \\
\hline & \multicolumn{12}{|c|}{ Dilution(Sample:Buffer) } \\
\hline & 2 & 4 & 8 & 16 & 32 & 64 & 128 & 256 & 512 & 1024 & 2048 & 4096 \\
\hline & $1: 1$ & $1: 2$ & $1: 4$ & $1: 8$ & $1: 16$ & $1: 32$ & 1:64 & $1: 128$ & $1: 256$ & $1: 512$ & $1: 1024$ & $1: 2048$ \\
\hline Crude extract & + & + & + & + & + & + & + & + & + & + & + & + \\
\hline Unbound lectin & + & + & + & + & + & + & + & + & + & - & - & - \\
\hline $\begin{array}{l}\text { MSL in mice } \\
\text { Erythrocytes }\end{array}$ & + & + & + & + & + & + & + & + & + & + & + & + \\
\hline Bovine & + & + & + & - & - & - & - & - & - & - & - & - \\
\hline Goat & - & - & - & - & - & - & - & - & - & - & - & - \\
\hline Human $\mathrm{O}^{+}$ & + & + & + & + & + & + & + & + & - & - & - & - \\
\hline Human O- & + & + & + & + & + & + & + & + & - & - & - & - \\
\hline Human A+ & + & + & + & + & + & + & + & + & - & - & - & - \\
\hline Human A- & + & + & + & + & + & + & + & + & - & - & - & - \\
\hline Human B+ & + & + & + & + & + & + & + & + & - & - & - & - \\
\hline Control & - & - & - & - & - & - & - & - & - & - & - & - \\
\hline
\end{tabular}

+ , Hemagglutination activity;-, Control.

\section{Conclusion}

This research article explained a simple and inexpensive method for the preparation of uniform sized agarose gel beads which was used as affinity chromatographic matrix. First of all conA was immobilized on agarose gel beads and used as a ligand of matrix to purify conA specific mulberry seed lectin (MSL) in single step by affinity chromatographic technique. The purified lectin is monomer in nature as judged by SDS-PAGE and migrated with single band. The molecular weight of the purified lectin was $22 \mathrm{kDa}$. This lectin strongly agglutinated with mice, chicken, bovine and human blood types $\mathrm{A}, \mathrm{B}$ and $\mathrm{O}$ erythrocytes respectively. There was no activity found on goat erythrocytes.

\section{Acknowledgements}

This research work has been partially funded by the Faculty of Engineering, University of Rajshahi and University Grants Commission of Bangladesh (sanction order no:52-5/52/UGC/Engg.-32/2015-2016).

\section{Conflict of Interest}

The authors declare that there are no conflicts of interests.

\section{References}

[1] D. K. Roper, E. N. Lightfoot, Separation of biomolecules using adsorptive membranes, J. Chromatogr. A 702 (1995) 326.

[2] H. Abou-Rebyeh, F. Korber, K. Schubert-Rehberg, J. Reusch, D. Josic, Carrier membrane as a stationary phase for affinity chromatography and kinetic studies of membrane-bound enzymes, J. Chromatogr. A 566 (1991) 341-350.

[3] R. Woker, B. Champluvier, M. R. Kula, Purification of $S$ oxynitrilase from Sorghum bicolor by immobilized metal ion affinity chromatography on different carrier materials, J. Chromatogr. B 584 (1992) 85-92.

[4] C. Charcosset, Purification of proteins by membrane chromatography, J. Chem. Technol. Biotechnol. 71 (2) (1998) 95-110.

[5] X. F. Zeng, E. Ruckenstein, Macroporous chitin affinity membranes for wheat germ agglutinin purification from wheat germ, J. Membr. Sci. 156 (1999) 97-107.

[6] D. Josic, J. Reusch, K. Loster, O. Raum, W. Reutter, High performance membrane chromatography of serum and plasma membrane proteins, J. Chromatogr. 590 (1992) 59-76.

[7] T. B. Tennikova, B. G. Belenkii, F. Svec, High-performance membrane chromatography a novel method of protein separation, J. Liq. Chromatogr. 13 (1990) 63-70.

[8] M. Unarska, P. A. Davies, M. P. Esnouf, B. J. Bellhouse, Comparative-study of reaction-kinetics in membrane and agarose bead affinity systems, J. Chromatogr. A 519 (1991) 53-67.

[9] N. Kubota, Y. Nakagawa, Y. Eguchi, Recovery of serum proteins using cellulosic affinity membrane modified by immobilization of Cu2+ ion, J. Appl. Polym. Sci. 62 (1996) 1153-1160.

[10] S. Sternberg, Therapeutic plasmapheresis membrane device, Proc. Am. Chem. Soc. Div. Polym. Mater. Sci. Eng. 61 (1989) 665-669.

[11] A. Malakian, M. Golebiowska, J. Bellefeuille, Purification of monoclonal and polyclonal IgG with affinity membrane matrix coupled with proteins A and G, Am. Lab. 40 (1993) 40.

[12] Sharon J, Kabat EA, Morrison SL, Studies on mouse hybridomas secreting IgM or IgA antibodies to alpha(1 to 6)linked dextran, Mol immunol. (1981); 18(9); 831-846. 
[13] N. Abser, T. Yeasmin, M. Salim Raza, S. Kumar Sarkar, F. Arisak, Single step purification, characterization and Nterminal sequences of a mannose specific lectin from mulberry seeds. Protein J. 24(2005)369-377.

[14] Zhengyi Wu, Zhe-Kun Zhou , Michael G. Gilbert. "Ficus elastica". Flora of China. Missouri Botanical Garden, St. Louis, MO \& Harvard University Herbaria, Cambridge, MA. Retrieved 29 August 2013.

[15] Burgess KS, Morgan M, De Verno LL, Husband CB, Asymmetrical introgression between two Morus species $(M$. alba, M. rubra) that differ in abundance. Mol. Ecol. 14(2005) 3471-3483.

[16] M. A. Hossain, S. M. R. Islam, N. Absar, Purification and characterization of lectins from mulberry seeds (Morus alba L.), Pakistan J Biol Sci. 7(2004) 1808-1813.

[17] E. Ruckenstein, W. Guo, Crosslinked mercerized cellulose membranes and their application to membrane affinity chromatography, J. Membr. Sci. 187 (2001)277-286.

[18] W. Guo, E. Ruckenstein, Crosslinked mercerized cellulose membranes for the affinity chromatography of papain inhibitors, J. Membr. Sci. 197(2002)53-62.

[19] W. Guo, E. Ruckenstein, Separation and purification of horseradish peroxidase by membrane affinity chromatography, J. Membr. Sci. 211(2003)101-111.
[20] U. K. Laemmli, Cleavage of structural proteins during the assembly of the head of bacteriophage T4. Nature, 227(5259) (1970)680-685.

[21] http://www.ruf.rice.edu/ bioslabs/methods/protein/biuret.html

[22] S. R. Kabir, A. Hossen, M. A. Zubair, M. J. Alom, F. Islam, A. Hossain, Y. Kimu, A new lectin from the tuberous rhizome of Kaempferia rotunda: I solation, characterization, antibacterial and antiproliferative activities, Protein Pept. Lett. 18(11)(2011)1140-1149.

[23] J. Chen, B. Liu, N. Ji, J. Zhou, H, J. Bian, C. Y. Li, F. Chen, J. K. Bao, A novel sialic acid-specific lectin from Phaseolus coccineus seeds with potent antineoplastic and antifungal activities, Phytomed. 16(4) (2009)352-360.

[24] A. K. M. Asaduzzaman, I. Hasan, A. Chakrabortty, Mst. S. Zaman, S. S. Islam, F. R. S. Ahmed, K. M. A. Kabir, M. Nurujjaman, M. B. Uddin, M. T. Alam, R. K. Shaha, S. R. Kabir, Moringa oleifera seed lectin inhibits Ehrlich ascites carcinoma cell growth by inducing apoptosis through the regulation of Bak and NF- $\mathrm{KB}$ gene expression, International Journal of Biological Macromolecules, 107 (2018) 1936-1944.

[25] Une S, Nonaka K, Akiyama J, Lectin Isolated from Japanese Red Sword Beans (Canavalia gladiata) as a Potential Cancer Chemopreventive Agent, Journal of food science, 83(3)(2018) 837-843. 